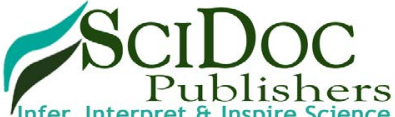

Publishers

\title{
Retrospective Study on Major Bovine Diseases and Financial Loss Due to Treatment in Wolaita Zone: A Case of Sodo Zuria District, Southern Ethiopia
}

Eshetu E*, Tilahun A, Thomas N, Awukew A

School of Veterinary Medicine, Wolaita Sodo University, Ethiopia.

\section{Abstract}

A retrospective study was undertaken at Sodo zuria district of Wolaita zone during November, 2015 to April, 2016 with the aim of to describe the important diseases and disorders observed in cattle and to assess and estimate the financial loss due to the treatment of such cases. For this purpose a 4 years data, from January, 2011 to December, 2015, were collected from patient register of sodo zuria district veterinary clinic case recording book. During the study, a total of 6105 cattle were examined and 21 various types of diseases and disorders were identified. The commonly found diseases were gastrointestinal worm infestation $(26.2 \%)$, trypanosomosis $(26.2 \%)$, infectious systemic problems (17.3\%), mixed infections $(12.2 \%)$, mastitis (9.2\%), ectoparasite infestation (6.5\%), pneumonia $(2.7 \%)$ and Lumpy skin disease $(1.1 \%)$. Rest of the diseases and disorders had lower percentage than $1 \%$. The occurrence of diseases and disorders were higher in female and young than male and adult animals, respectively. Internal parasite infestation found to be the most prevalent cattle diseases among all groups of cattle, which was followed by trypanosomosis and infectious systemic problem. For the treatment and management of 6105 patient cattle, different types of antibiotics, antihelminthics, antiprotozoal, acaricides, disinfectants and multivitamins were used. The total estimated financial loss was found to be 147,844.00 Ethiopian birr (ETB) and high amount of money was lost because of antiprotozoal purchase $(52,032.54 \mathrm{ETB})$. Thus, these diseases and disorders were found that they cause a considerable financial loss due to treatment of the affected animals. This study suggests that implementing control programs targeting these diseases and disorders and conducting further retrospective epidemiologic analysis for a long period of years to identify risk factors of diseases and exact economic impact will help to reduce the occurrence and the direct and indirect economic loss due to this diseases and disorders in this area.

Keywords: Cattle; Diseases; Financial Loss; Retrospective Study; Treatment.

Abbreviations: ETB: Ethiopian Birr; SNNPR: Southern Nations, Nationalities and People Regional State.

\section{Introduction}

The contribution of livestock to the human being particularly in the developing countries is enormous and ruminants are an important component of livestock production in Africa. They are a major source of food protein income savings, fiber and manure [1]. Similarly, the dominant economic feature of Ethiopia is its agricultural sector and more than $80 \%$ of its population plays a significant role, of which livestock is an essential component [2]. Like in many developing countries, domestic animals play a crucial role in Ethiopia. They provide food in the form of meat and milk, and non-food items such as draft power, manure and transport services as inputs into food crop production and fuel for cooking. Livestock are also a source of cash income through sales of the above items, animal hides and skins. Furthermore, they act as a store of wealth and determine social status within the community $[3,4]$.

Ethiopia is known for its high livestock population, being the first in Africa and tenth in the world [3, 4] and among the livestock population, there are about 53.4 million heads of cattle; 25.5 million sheep, 22.78 million goats and 44.9 million poultry [5]. The population of these animals in Wolaita zone is 886,242 cattle, 117,274 sheep, 99,817 goats, 1951 horses, 2174 mules, 54,209 donkeys and 442,428 poultry [6]. Despite the large number of livestock in the area the sector is characterized by low productivity and, hence, income derived from this sector of agriculture could not impart significant role in the development of the region's economy.

\author{
*Corresponding Author: \\ Eyob Eshetu, \\ School of Veterinary Medicine, Wolaita Sodo University, Ethiopia. \\ E-mail: eyobeshetu@ymail.com \\ Received: June 29, 2018 \\ Accepted: July 24, 2018 \\ Published: July 30, 2018
}

Citation: Eshetu E, Tilahun A, Thomas N, Awukew A. Retrospective Study on Major Bovine Diseases and Financial Loss Due to Treatment in Wolaita Zone: A Case of Sodo Zuria District, Southern Ethiopia. Int J Vet Health Sci Res. 2018;6(1):225-229. doi: http://dx.doi.org/10.19070/2332-2748-1800044

Copyright: Eshetu $\mathbf{E}^{\circ}$ 2018. This is an open-access article distributed under the terms of the Creative Commons Attribution License, which permits unrestricted use, distribution and reproduction in any medium, provided the original author and source are credited. 
The low productivity is attributed to low genetic potential of indigenous breeds, inadequate management, poor nutrition and reproductive performance, insufficient pasture land, lack of technical expert, insufficient supply of vaccine, lack of epidemiologic study and shortage of government employee in the field level and high incidence of various diseases of different systems of animals. Among these constraints, diseases have numerous influences on productivity and fertility of herds as well as interfering with the development of healthy livestock and livestock industry in our country [7,8]. Disease is defined as inability to perform physiological functions at normal levels even though nutrition and other environmental requirements are provided at adequate levels [9]. Disease also causes nutritional deficiency and disturbances in fertility. The effect of livestock diseases could be expressed in terms of losses due to mortality and morbidity, loss of weight, slow down growth, poor fertility performance and decrease physical power. If the livestock sector develops, it will be able to fulfill the existing requirement of protein for the country.

Understanding on the incidence, prevalence, distribution, determinants or risk factors and direct and indirect economic and financial losses of diseases in an area is necessary to plan systemic health program or formulate effective control strategies. However, technological difficulties in these countries hinder extensive use of modern diagnostic techniques in disease surveillance [10]. Retrospective evaluation of clinical case records help to understand the predominant clinical problems and also their demographic and seasonal distribution in a particular area [11]. Therefore, studying diseases of animals retrospectively is a rapid and cheap means to identify the strategy of effective disease control when it is analyzed statistically. Hence, such knowledge is essential in planning control strategies against livestock diseases. Therefore, the current study was conducted with the objectives of describing important diseases and disorders observed in cattle, to elucidate the top ten diseases and disorders observed in different age and sexes of cattle as well as to assess and estimate the financial loss due to the treatment of cattle diseases and disorders.

\section{Materials and Methodology}

\section{Study Area}

The study was conducted at Sodo zuria district of Wolaita zone from November, 2015 to April, 2016. This district is one of the 13 districts of Wolaita zone in Southern Nations, Nationalities and People Regional State (SNNPR), Southern Ethiopia, which is located $390 \mathrm{~km}$ away from Addis Ababa in southern direction and it has a latitude and longitude of $6^{\circ} 54^{\prime} \mathrm{N} 37^{\circ} 45^{\prime} 54 \mathrm{~N} 3745 \mathrm{E}$ with an elevation between 1650 and 2980 meter above sea level. The district is bounded with Damot Gale district to the north, Humbo district to the south, Damote Woide district to east and Damote Sore district to the west; the annual rainfall and temperature of the area is $1000-1200 \mathrm{~mm}$ and $25-35^{\circ} \mathrm{C}$, respectively. The area is categorized under woina dega agro ecological climate. The dry season extends from September to February and rain season stay from March to August. The livestock population of the area comprised about 1,097, 710 cattle; 150,383 sheep; 185,250 goat; 60,055 equine and 734,924 poultry [11].

\section{Study Population}

For the present retrospective study, cattle of both sexes, all age groups and kept under any management system; and presented to Sodo zuria district veterinary clinic by their owners and registered on case record book were considered.

\section{Study Design and Sampling Methods}

Sources and Nature of Data: The retrospective study of diseases in cattle was done in Sodo zuria district. For this purpose a 4 years data, from January, 2011 to December, 2015, were collected from patient register of Sodo zuria district veterinary clinic case recording book. Clinical records are kept at Sodo zuria district veterinary clinic for all livestock disorder cases treated by staff veterinarians and animal health workers. Usually, animals seen by clinicians are sick animals presented by farmers. Thus, from these record books all cases for bovine species were considered. The data were checked manually for obvious inconsistencies, recording errors or missing data. The potential errors were evaluated and corrected. Data with suspicious values were excluded. The age, sex, type of disease; and the total dose and types of drugs used for the treatment of each patient cattle were collected from the register.

\section{Data Analysis}

All collected data from the patient recording book was recorded properly and these data were entered into Microsoft Excel spreadsheet computer program to create database. Data on all aspect of the above objectives were collected properly, handled carefully and analyzed retrospectively and interpreted to compute frequency of diseases and disorders and percentage of summarized data were presented, and expressed in tabular form. For the analysis of data, statistical software program: SPSS-20 for windows version was used. The total financial loss as a result of treatment was estimated and computed using the model:

\section{$\mathrm{L}=(\mathrm{Ni} \times \mathrm{P} \mathrm{j})$}

Whereas, $\mathrm{L}=$ total financial loss, $\mathrm{Ni}=$ total amount of each types of drugs used for treatment of cattle presented to Sodo zuria district veterinary clinic and $\mathrm{Pj}=$ the current average price of each drug at the clinic throughout the four year of the study.

\section{Results}

\section{Distribution of Diseases and Disorders Observed in Cattle of the Study Area}

The overall diseases and disorders observed in cattle the study area are shown in the Table-1 below. In the study it was found that 6105 cattle were suffering from 21 various diseases and disorders, where maximum numbers of cattle, 1791 (26.3\%) and 1790 (26.2\%) were affected by trypanosomosis and worm infestation, respectively. The study also revealed only three cases of diseases (Brucellosis) as well as two numbers of diseases (Salmonellosis, Coccidiosis and Fasciolosis) was found. It was exerted from the study that Ringworm, Babesiosis and Demodicosis were recorded as single case from the studied cattle during the study period in the sodo zuria district of Wolaita zone. 


\section{Age and Sex Wise Distribution of Diseases and Disorders Observed in the Study Area}

During the study top ten cattle diseases and disorders were ranked in relation to cattle age and sex. Accordingly, results acquired from the study point out that worm infestation, trypanosomosis infection and infectious systemic problem were more frequent in all the studied age groups of cattle as compared with other diseases and disorders. The study also gave interesting phenomena that cattle of young age were mostly susceptible to gastrointestinal parasite infection, trypanosomosis and ectoparasite infestation in contrast of cattle of other studied age. Table 2 below describes details of the prevalence variation between the two age groups.

Sex wise diseases and disorders in cattle were also considered and the study revealed that female cattle were highly affected with diseases and disorder (Table 2). Likely in sex based phenomena; worm infestation, trypanosomosis infection and infectious systemic problems were also ranked as the most frequent in case of both sexes in the studied areas.

\section{Estimated Financial Loss Due to Disease and Disorder Treatment}

In this study, financial loss due to the treatment of diseases and disorders were assessed. For this purpose, the volume of the drugs prescribed and their respective current market prices in the study area were used as parameters for the calculation of the total financial loss due to treatment (Table 3). For the treatment and management of 6105 various cases, different types of antibiotics, antihelminthics, antiprotozoal, Acaricides, disinfectants and multivitamins were used. The total estimated financial loss was found to be 147,844.00 Ethiopian birr (ETB) and high amount of money was lost because of antiprotozoa purchase (52,032.00ETB) followed by money lost for the purchase of antibiotics $(43,125.80$ ETB), acaricides (30,520.00ETB) and the lowest amount of money was lost for multivitamins purchase (396.80ETB).

\section{Discussion}

Retrospective studies are much cheaper as the data have already been collected. One advantages of such a study design is the lack of bias because the outcome of current interest was not the original reason for the data to be collected. Because the cohort was originally constructed for another purpose it is unlikely that all the relevant information will have been rigorously collected. The study period may be many years but the time to complete the study is only as long as it takes to collate and analyses the data.

Accordingly, in this study a retrospective study involving the analyses of four years data (January, 2011 to December, 2015) of cattle treated for different diseases and disorders was conducted from October, 2015 to April, 2016 in Sodo zuria district of Wolaita zone. The data was collected from case book record of the veterinary clinic and a total of 6105 cases were included in the study. Out of the total cases observed, 4102 were female and 2003 male.

From the study, 21 various diseases and disorders were observed and broadly grouped in to protozoal, bacterial, viral, internal parasite and non infectious disease. The highest frequency of

Table 1. The diseases and disorders of cattle observed in the study area.

\begin{tabular}{|c|c|c|}
\hline Major disease & No. of animal & frequency \\
\hline GIT parasite & 17901 & 26.3 \\
\hline Trypanosomosis & 1790 & 26.2 \\
\hline Infectious (systemic disease) & 591 & 19.2 \\
\hline Mastitis & 627 & 9.2 \\
\hline Mixed infection & 478 & 7.0 \\
\hline Ectoparasite infestation & 440 & 6.5 \\
\hline Pneumonia & 185 & 2.7 \\
\hline LSD & 77 & 1.1 \\
\hline Food poison & 44 & 0.6 \\
\hline Mechanical Injury & 36 & 0.5 \\
\hline Black leg & 13 & 0.2 \\
\hline Dermatitis & 11 & 0.2 \\
\hline Bloat & 8 & 0.1 \\
\hline Fasciollosis & 2 & 0.03 \\
\hline Salmonellosis & 2 & 0.03 \\
\hline Dermatophilosis & 2 & 0.03 \\
\hline Coccidiosis & 2 & 0.03 \\
\hline Brucellosis & 1 & 0.043 \\
\hline Babesiosis & 1 & 0.015 \\
\hline Ringworm & 1 & 0.015 \\
\hline Demodicosis & 1 & 0.015 \\
\hline
\end{tabular}


Table 2. The top ten diseases and disorders in relation to age and sex of cattle.

\begin{tabular}{|c|c|c|c|c|}
\hline \multirow{2}{*}{ Major top ten disease } & \multicolumn{4}{|c|}{ Variable factors } \\
\cline { 2 - 5 } & \multicolumn{2}{|c|}{ Age } & \multicolumn{2}{c|}{ Sex } \\
\cline { 2 - 5 } & Young & Adult & Male & Female \\
\hline GIT parasite & $978(14.3 \%)$ & $813(11.9 \%)$ & $563(8.03 \%)$ & $1228(18.0 \%)$ \\
\hline Trypanosomosis & $1201(17.6 \%)$ & $589(8.6 \%)$ & $586(8.6 \%)$ & $1204(17.7 \%)$ \\
\hline Infectious (systemic diseases) & $591(8.7 \%)$ & $716(10.5 \%)$ & $525(7.7 \%)$ & $782(11.5 \%)$ \\
\hline Mixed infection & $293(4.3 \%)$ & $185(1.9 \%)$ & $526(2.7 \%)$ & $781(4.3 \%)$ \\
\hline Mastitis & $110(1.6 \%)$ & $517(7.6 \%)$ & $45(0.7 \%)$ & $582(8.5 \%)$ \\
\hline Ectoparasite infestation & $361(5.3 \%)$ & $79(1.2 \%)$ & $176(2.6 \%)$ & $264(3.9 \%)$ \\
\hline Pneumonia & $7.3(1.1 \%)$ & $112(1.6 \%)$ & $62(1.0 \%)$ & $123(1.8 \%)$ \\
\hline LSD & $14(0.26 \%)$ & $63(0.9 \%)$ & $35(0.5 \%)$ & $42(0.6 \%)$ \\
\hline Food poison & $22(0.3 \%)$ & $22(0.3 \%)$ & $22(0.35 \%)$ & $22(0.3 \%)$ \\
\hline Mechanical injury & $14(0.2 \%)$ & $21(0.3 \%)$ & $14(0.2 \%)$ & $21(0.3 \%)$ \\
\hline
\end{tabular}

Table 3. Estimated financial losses due to treatment in different ways of drug prescription.

\begin{tabular}{|c|c|c|c|c|}
\hline Types of drug & Drug description & Total dose & Unit price & Total price \\
\hline \multirow{4}{*}{ Types of antibiotic } & Oxy TTC $(10 \%$ and $20 \%)$ & $55,200 \mathrm{ml}$ & 0.65 cent $/ \mathrm{ml}$ & $35,880.00$ \\
\hline & Pinstripes & $6640 \mathrm{ml}$ & $0.91 \mathrm{cent} / \mathrm{ml}$ & $6,042.40$ \\
\hline & Alomycine & $1420 \mathrm{ml}$ & 0.45 cent $/ \mathrm{ml}$ & 639.00 \\
\hline & Spray & $830 \mathrm{ml}$ & 0.68 birr $/ \mathrm{ml}$ & 564.40 \\
\hline \multirow{4}{*}{ Antihelminthics } & Tetraclozanole & 763bolus & 2bir/bolus & $1,526.00$ \\
\hline & Albendazole $2500 \mathrm{mg}$ & 4611bolus & $1.70 /$ bolus & $7,838.70$ \\
\hline & Albendazole 300mg & 2388bolus & $1.80 /$ bolus & $4,298.40$ \\
\hline & Ivermectine & $2911 \mathrm{ml}$ & 0.16 cent $/ \mathrm{ml}$ & 465.76 \\
\hline \multirow{3}{*}{ Antiprotozoal } & Veridium & $2918 \mathrm{ml}$ & 4.03bir $/ \mathrm{ml}$ & $11,759.54$ \\
\hline & Ethedium & 2723bolus & 11bir/bolus & $29,953.00$ \\
\hline & Bovidium & 1290bolus & 8bir/bolus & $10,320.00$ \\
\hline Acaricides & Diazinol 60\%EC & $218000 \mathrm{ml}$ & $0.14 \mathrm{birr} / \mathrm{ml}$ & $30,520.00$ \\
\hline \multirow{3}{*}{ Disinfectants } & Savlon & $16000 \mathrm{ml}$ & $0.15 \mathrm{birr} / \mathrm{ml}$ & $2,400.00$ \\
\hline & Alcohol & $36000 \mathrm{ml}$ & $0.09 \mathrm{birr} / \mathrm{ml}$ & $3,240.00$ \\
\hline & Iodine & $4000 \mathrm{ml}$ & $0.5 \mathrm{birr} / \mathrm{ml}$ & $2,000.00$ \\
\hline Others & Multivitamin & $496 \mathrm{ml}$ & $0.8 \mathrm{cent} / \mathrm{ml}$ & 396.80 \\
\hline \multicolumn{4}{|c|}{ Total estimated financial loss } & $147,844.00 \mathrm{ETB}$ \\
\hline
\end{tabular}

occurrence corresponded to the number of registered cattle are protozoa $(26.2 \%)$, internal parasite $(26.3 \%)$ and bacterial $(10 \%)$. The occurrence of diseases was higher in female and young than male and adult, respectively. Internal parasite infestation was found to be the most prevalent $(26.3 \%$ ) cattle disease, followed by trypanosomosis $(26.2 \%)$ and infectious $(19.2 \%)$. This finding is in line with previous results of [13] who reported the prevalence of trypanosomosis as $28.1 \%$ and $27.3 \%$ in young and adult animals respectively.

The current study showed that the trypanosomosis $(26.2 \%)$ were frequently occurred disease in the study area. This result was in agreement with finding of [14] reported as $28.1 \%$ bovine trypanosomosis. The higher prevalence of trypanosomosis in present survey might be due to lack of integrated tsetse and trypanosomosis control action or presence of cyclical or mechanical vectors in study area.
The present retrospective study conducted in Sodo zuria district veterinary clinic was used for to identify the top ten diseases and their association in relation to sex and age of cattle. Moreover, the financial loss due to the treatment of the above mention disease indicated that the community losses (Veridium ethedium bovidium) antihelment (Albendazole and Ivermectine) were common drug used. Retrospective study of clinic case records serves a valuable role in estimation of a health facility's disease burden communication among clinicians on patient's conditions and planning on health facilities management and personnel development [15].

In the present study, the total financial loss due to treatment of different diseases was assessed antibiotic (43,125.80ETB) anthelmintic $(141,28.86 .00 \mathrm{ETB})$ antiprotozoal (52032.54ETB) acaracide (30,520.ETB) disinfectant (7640.00ETB) other or 
multivitamin (396.80ETB). As result use of different drugs was calculated the total price $147,844.00$ ETB.

\section{Conclusion and Recommendations}

Based on the results of this retrospective study of cattle diseases and disorders conducted in Sodo zuria district, 21 various diseases and disorders of cattle were found. Accordingly, internal parasite infestation was found to be the most prevalent $(26.3 \%)$ cattle disease, followed by trypanosomosis $(26.2 \%)$ and infectious systemic problems (19.2\%). Occurrence of almost all diseases and disorders were higher in female and young than male and adult animals, respectively. Antibiotics, antihelminthics, antiprotozoal, acaricides, disinfectants and multivitamins were the different types of drugs and chemicals used for the treatment and management of various diseases and disorders. The total estimated financial loss was found to be $147,844.00$ Ethiopian birr (ETB) and high amount of money was lost because of antiprotozoa purchase (52,032.54ETB). Thus, these diseases and disorders in the study area were found that they cause a considerable financial loss due to treatment of the affected animals. Therefore, based on the above conclusions the following recommendations are forwarded: Control programs targeting these diseases and disorders should be implemented and local education programs and awareness about these diseases should be established. The concerned bodies should also have to supply adequate amount of drugs and chemicals for the treatment and management of the above mentioned disease and disorders. Further retrospective epidemiologic analysis of diseases for a long period of years will help to identify risk factors of diseases and exact economic impact, which will help to initiate efficient control program.

\section{References}

[1]. Waruru RM, Mutune MN, Otieno RO. Gastrointestinal parasite infections of sheep and goats in a semi-arid area of Machakos District, Kenya. Bull Anim Health Prod Afr. 2005;53(1):25-34.

[2]. Ayelet G, Gelaye E, Negussie H, Asmare K. Study on the epidemiology of foot and mouth disease in Ethiopia. Rev Sci Tech. 2012 Dec;31(3):789-98. PubMed PMID: 23520733.

[3]. Mekonnen G, Forssido T, Gebre-Wold A, Dagnachew Z, Anteneh A. The Ethiopian livestock industry: Retrospects and prospects. IAR proceedings, Addis Ababa, Ethiopia. 1989.

[4]. Gebrecherkos BA. Prevalence of bovine fascilosis in municipal Abbatoir of Adigrat, Tigray, Ethiopia. REDVET. 2012;13(9).

[5]. CSA. Federal Democratic Republic of Ethiopia Central Statistical Agency agricultural Sample Survey. Report on livestock and livestock characteristic (private peasant holding). Stat Bull 505. Addis Ababa. 2011;2:1-190.

[6]. Wolaia Zone Agricultural Office (WZAO). Livestock statistical data of Wolaita zone, Wolaita zone Agricultural Office Livestock and Natural Resource development team; 2013.

[7]. Abera M, Mohammed T, Abebe R, Aragaw K, Bekele J. Survey of ixodid ticks in domestic ruminants in Bedelle district, Southwestern Ethiopia. Trop Anim Health Prod. 2010 Dec;42(8):1677-83. doi: 10.1007/s11250-0109620-4. PubMed PMID: 20563884.

[8]. Bekele J, Tariku M, Abebe R. External parasite infestations in small ruminants in Wolmera District of Oromiya Region, Central Ethiopia. J Anim Vet Adv. 2011;10(4):518-23.

[9]. Radostitis OM, Gay CC, Blood DC, Hinchcliff KW. Veterinary medicine: A textbook of the diseases of cattle, sheep, pigs, goats and horses. WB Saunders company: Philadelphia. USA; 2000. p.572-7.

[10]. Tisdell C. Economics of controlling livestock diseases: basic theory. The University of Queensland School of Economics; 2006 Nov 1.

[11]. Wolaita Sodo District Agricultural development organization (WSDADO). Annual report on total livestock population, weather and climate of the Wolaita Soddo District Agricultural development, Southern Ethiopia; 2013.

[12]. Mann CJ. Observational research methods. Research design II: cohort, cross sectional, and case-control studies. Emerg Med J. 2003 Jan;20(1):54-60. PubMed PMID: 12533370.

[13]. Zeryehun T, Abraham Z. Prevalence of bovine trypanosomosis in selected district of Arba Minch, SNNPR, Southern Ethiopia. Global Veterinaria. 2012;8(2):168-73.

[14]. Mulaw S, Addis M, Fromsa A. Study on the prevalence of major trypanosomes affecting bovine in tsetse infested Asosa District of Benishangul Gumuz Regional State, Western Ethiopia. Global Veterinaria. 2011;7(4):330-6.

[15]. Noteboom C, Qureshi S. Adaptations of electronic health records to activate physicians' knowledge: how can patient centered care be improved through technology?. Health and Technology. 2014 May 1;4(1):59-73. 